\title{
EMIGRAÇÃO PORTUGUESA OLHARES SOBRE A AUSÊNCIA: UMA PERSPECTIVA DIACRÓNICA
}

\author{
Maria Manuela AGUIAR \\ Associação Mulher-Migrante
}

Recibido: 07/04/2011

Aceptado: 20/07/2011

RESUMO: A ausência significava, no paradigma "territorialista" tradicional, a ruptura com a sociedade do país e a perda de direitos de cidadania, direitos políticos, sociais e culturais. Os ausentes eram despojados da própria nacionalidade, se adquirissem uma outra. Porém, o carácter automático da recuperação da nacionalidade, em caso de retorno definitivo, indicava que o legislador oitocentista se dava conta da subsistência dos laços de ligação à pátria durante o período de ausência.

Para a progressiva tomada de consciência das formas de vencer o distanciamento físico pela presença dos emigrantes na vida da sociedade portuguesa contribuíram, antes de mais, as remessas, os investimentos, as dádivas para a melhoria das suas terras. Mais tardio foi o reconhecimento de uma outra forma de presença, através da criação, no exterior, de espaços de língua e cultura portuguesa.

A democratização do país, em 1974, veio permitir a transição progressiva para o paradigma "personalista", em que os expatriados gozam de um novo estatuto de direitos, tendencialmente igual aos dos residentes, e as comunidades do estrangeiro são vistas como parte integrante do património cultural da Nação.

PALAVRAS CHAVE: paradigma "territorialista", ausência, perda de direitos, paradigma "personalista", direitos iguais aos dos residentes.

\section{PORTUGUESE EMIGRATION, LOOKS ON THE ABSENCE: A DIACHRONIC PERSPECTIVE}

ABSTRACT: The absence meant, in the traditional "territorial" paradigm, the rupture with the society of the country and the lost of citizenship rights, as well as, political, social and culture rights. The absent ones would be stripped from their own nationality, if they acquired another one. However, the automatic character of the recuperation of their nationality, in case of definitive return, indicated that the legislator from the XVIII century was aware of the subsistence of the connecting bounds to the native country during the absence period. The consignments, the investments and the gifts for the improvement of their land contributed, first of all, for the progressive awareness about the ways of overcoming the physical detachment through the presence of the emigrants in the life of Portuguese society. The recognition of another way of presence came later, through the establishment, in the exterior, of spaces of Portuguese language and culture. The democratisation of the country, in 1974, came to allow the progressive transition to the "personal" paradigm, in which the expats enjoy a new status of rights, that tend to be equal to the residents' rights, and the foreign communities are seen as an integrant part of the Portuguese nation. 
KEY WORDS: "territorial" paradigm, absence, loss of rights, "personal" paradigm, equality of rights that residents.

\section{INTRODUÇÃO}

Abordo neste trabalho a forma como as migrações portuguesa foram vistas, no país - pelo legislador, em primeira linha, mas também por políticos, estudiosos, opinião pública - ao longo do largo período, que cabe no conceito de emigração, em sentido estrito, excluindo o tempo da Expansão, e da colonização, designadamente da colonização do Brasil, muito embora se deva reconhecer a importância do passado distante, de onde vem a tradição de partir para longe, como meio ideal de resolver problemas de sobrevivência, de emprego, de ascensão social, de enriquecimento supostamente fácil... Houve, de facto, uma linha de continuidade nessa tradição multissecular, e na forma como os expatriados se envolveram na vida das sociedades de destino, (parecendo sempre mais ousados e mais solidários, quando fora do um pequeno território, de horizontes limitados...), assim como no modo de se relacionarem com a terra de origem, para ela enviando uma infinidade de pequenas economias, e, mais raramente, mas com formidável impacte, grandes fortunas, com elas ajudando as famílias, o desenvolvimento das comunidades locais e o equilíbrio das finanças públicas.

Assim se compreende que, após a independência do Brasil, os fluxos migratórios espontâneos não tenham sofrido nem desvio nem diminuição, bem pelo contrário. Assim se explica, igualmente, o favorecimento do destino brasileiro, território estrangeiro, em detrimento das colónias de África, por uma corrente da "inteligentzia" portuguesa conhecedora desta harmónica transição do papel de colonizador para o de emigrante.

Ao delimitar aquele período temporal, não deixo de lhe atribuir carácter, até certo ponto, artificial, tanto mais quanto a posição do legislador sobre o excesso dos fluxos de saída se mantém praticamente inalterada. De facto, desde as Ordenações Filipinas até meados do século XX, as manifestações de actividade legislativa, ou o que poderemos chamar políticas de emigração, foram pouco mais do que medidas proibitivas ou limitativas de um movimento, que assumia a feição de um êxodo desmesurado.

Políticas de verdadeira protecção e de reconhecimento dos direitos de cidadania dos expatriados não houve, embora tenha havido preocupação, e, em abundância, estudos, debates, polémicas, chamadas de atenção - inclusivamente no próprio parlamento, com a constituição de duas comissões parlamentares de inquérito no século XIX. As conclusões e os remédios propostos, nomeadamente pela comissão parlamentar em 1872, não foram, porém, levados a cabo... O mesmo se diga de muitas outras propostas, algumas de 
investigadores ou especialistas neste domínio, que foram também políticos, como Oliveira Martins e Afonso Costa. Muitas das observações e dos projectos, que não conseguiram executar, mantiveram actualidade ou vieram, embora muito tardiamente, na actualidade, a ser contempladas na Lei. Mas em outros aspectos, como será sublinhado, foram "homens do seu tempo" e não conseguiram dar a uma realidade migratória, a formas de "ausência"não fundamentalmente diferentes das que ainda agora conhecemos, o tratamento de que somos capazes na actualidade, no campo do Direito.

Neste trabalho percorreremos vários ciclos da vida da emigração, que mais do que seria expectável, se encadeiam e se aproximam na psicologia das gentes, no seu comportamento face ao país, na organização social do espaço que habitam no estrangeiro, criando o seu próprio "mundo português", dentro de outros mundos em que interagem e se integram, as mais das vezes, bem.

As "situações de facto" em que as múltiplas formas de"presença dos ausentes" se afirmam, multi-secularmente, dentro e fora do país, só se convertem em "situações jurídicas" no nosso tempo - no sentido de gerarem direitos individuais e um novo relacionamento entre Estado e os cidadãos, entre o Estado e as instituições da "sociedade civill": escassas décadas de rápida transformação das ideias e das leis, que rompem com séculos de denegação jurídica e de descaso político! Um "encontro dos cidadãos com a lei", poderíamos dizer, parafraseando Jean Carbonnier.

O novo "direito dos expatriados", irradia no cerne de uma concepção "personalista", por oposição ao tradicional paradigma "territorialista"e é produto da nossa época - tendo ganho progressivamente terreno no panorama europeu, como se constata na perspectiva de direito comparado, muito embora seja, ainda, sede de particularismos nacionais. O caso português é, com alguns dos seus arcaísmos, combinados com laivos de pioneirismo, certamente merecedor de registo, e oferece aos interessados um campo de observação alargado a séculos de intenso movimento, de mutações, mas também de surpreendentes constantes na vida e na acção dos indivíduos.

Neste ramo emergente do Direito, em via de sólido enraizamento, confrontam-se, ainda, diferentes olhares, visões plurais, no plano nacional e internacional. Tenho a minha - como jurista e como participante, ao longo de um quarto de século, em muitos dos colectivos por onde passou o processo legislativo em Portugal e até, também, a nível europeu, no Conselho da Europa e com ela escrevo as linhas que se seguem. 


\section{A EMIGRAÇÃO COMO AUSÊNCIA}

«Não nos admiremos. Eram as ideias do tempo.» Affonso Costa

\section{I.1. A Ausência, na Sociedade e no Direito}

O fenómeno das migrações, sempre multifacetado, envolve componentes muito diversas, em que as formas de ausência e de presença (presença física, mas não só, também afectiva, sentimental, económica, cultural...) se sobrepõem ou se interligam, no plano individual como colectivo, e vão sendo percebidas, ao longo de épocas ou de ciclos, muito diferentemente.

Numa abordagem tradicional, a ausência implica fatalmente uma ruptura, conotada com o abandono ou a desistência de fazer vida e carreira na própria terra. Olhada a emigração por parte de quem fica, assim foi, e em certa medida ainda é, na opinião pública, no juízo do povo e dos vizinhos, assim como em correntes doutrinais mais resistentes a uma nova visão das coisas.

Completamente oposta foi, através dos tempos, a perspectiva, o sentir comum dos próprios emigrantes - aliás, abundantemente expresso em gestos de solidariedade e em directos contributos para o bem-estar das famílias e das comunidades locais, em comportamentos reveladores da ligação à terra de origem, que são uma constante na história da emigração portuguesa dos últimos dois séculos e, a meu ver, até também nos períodos antecedentes. De facto, o móbil de procurar, lá fora, progresso e fortuna e de a repartir com os seus, é compatível com qualquer dos enquadramentos do movimento de expatriação, que conhecemos historicamente - o esforço de colonização empreendido ou incentivado pelo Estado, ou a demanda individual, espontânea, de trabalho no estrangeiro. Autores de diferentes épocas, dão-se conta desta realidade, desde Oliveira Martins, ou Afonso Costa (COSTA, 1911:243), até aos nossos contemporâneos Miriam Halpern Pereira ou Joel Serrão (SERRÃO, 1974: 110).

Mas nem os governantes do Reino, nem, posteriormente os da República e do "Estado Novo", nem sequer os doutrinadores, em cada um desses períodos, fizeram questão de aventar ou conceder contrapartidas ao contributo dos expatriados, pelo menos no domínio do exercício da cidadania.

O universo jurídico é um mundo formal, aparentemente fechado sobre si próprio, com vocação original para a estabilidade, mas capaz de evolução, nos diversos ramos do Direito, nomeadamente no que respeita às migrações. Constata-se, porém que, entre nós, mudou pouco ao longo de séculos, porque o legislador se limitou a seguir conceitos e preconceitos firmados e não pro- 
curou fazer pedagogia ou induzir transformações (objectivo ao seu alcance, mas mais fácil em períodos de mudança radical de regime político e constitucional, como foi o posterior à revolução de 1974, em Portugal - o primeiro, aliás, a tornar-se portador de inovação significativa nas políticas de emigração, ao contrário do que acontecera na transição da Monarquia para a República, e da República para a ditadura).

O peso que os emigrantes iam ganhando na economia do País foi amplamente reconhecido, mas não do ponto de vista jurídico. O nosso ordenamento ignorou, pura e simplesmente, a prevalência dos laços de ligação à terra sobre a força de dissolução atribuída ao afastamento. A saída para o estrangeiro continuou a ser, obstinadamente, vista como um corte com a comunidade nacional, se não mesmo como uma deserção. Por isso, a ausência, ainda que temporária, tinha repercussão imediata na esfera do Direito: total suspensão do exercício de direitos políticos, principal atributo da cidadania e cessação de quaisquer prestações e apoios do Estado, no campo social e cultural - restando uma incipiente protecção consular (cuja insuficiência foi, vezes sem conta, denunciada pelos próprios diplomatas, em ofícios, que podem ser consultados nos arquivos do Ministério dos Negócios Estrangeiros).

O Estado começou por cuidar, fundamentalmente, desde o início da Expansão, de diminuir o caudal imparável dos fluxos migratórios, com medidas proibitivas os restritivas (SERRÃO, 1974:106). Só mais tarde, já em pleno século XX, sobretudo na segunda metade, se nota a preocupação de, a par do controlo dos movimentos migratórios, assegurar aos emigrantes um apoio centrado no acompanhamento e fiscalização das condições de transporte marítimo - como é sabido, causa de muitas queixas, sofrimentos e fatalidades, que faziam notícia frequente na imprensa. Maria Beatriz Rocha Trindade denomina-as, expressivamente, "políticas de trajecto de ida". De facto, a protecção cessava no fim da viagem transoceânica, ficando os homens, a partir daí, entregues a si próprios, face às dificuldades que quase sempre os esperavam.

Neste contexto sociopolítico, não surpreenderá que, apesar da influência que a emigração teve, e tem, na sociedade portuguesa - com cerca de um terço da população a viver fora do País, desde o século XVI - não haja sido dado tratamento autónomo e sistematizado aos efeitos da ausência dos cidadãos no exterior, onde, em regra, permaneciam com morada conhecida, em contacto com familiares e amigos.

A temática da ausência, de que se ocupava, demoradamente, o Código Civil de 1867, era apenas a que configurava o desaparecimento "em parte incerta" (artigos $55^{\circ}$ a $96^{\circ}$ do Código Civil). A "ausência", nesse sentido, tanto 
podia verificar-se no contexto da emigração como não, pois, como é óbvio, o facto de uma eventual "evasão" para "parte incerta" no estrangeiro não precludia a aplicação da lei geral...

Mudámos, entrementes, o Código Civil, em consecutivas reformas, de maior ou menor monta, mas ainda hoje não é, em primeira linha, nesse Código, mas na Constituição e em outras leis, como as eleitorais, ou como as que regem o regime de segurança social, de fiscalidade, de serviço militar ou de ensino, que terá de procurar-se a regulamentação dispersa de um "estatuto dos ausentes", composto pelos seus direitos e deveres - que o mesmo é dizer as formas de valoração jurídica da ausência ("hoc sensu"). Acrescente-se também o direito penal, já que a emigração clandestina foi criminalmente sancionada quase até ao termo do chamado "Estado Novo" - questão não despicienda, pois se estima em cerca de um terço do total, através dos vários ciclos migratórios, os que afrontavam as normas proibitivas da saída...

A liberdade de circulação, aclamada ao nível dos princípios, desde o advento da Monarquia Constitucional, era, contudo, de facto, obstaculizada por múltiplos expedientes burocráticos, por regulamentação prevendo taxas e alcavalas, pelo custo desmesurado de passaportes (COSTA, 1911:166). E, como já acentuei, só se alcança em Portugal, plenamente, com a Constituição de 1976.

$\mathrm{O}$ estatuto dos ausentes era, pois, repito, de sinal negativo, consistindo no esvaziamento de direitos políticos e, em regra, de direitos às prestações do Estado nacional, em todos os sectores, do social ao cultural. A ida para o estrangeiro significava uma verdadeira "capitis diminutio" - o interesse dos indivíduos, mormente o seu direito de emigrar, era subordinado ao interesse público, tal como foi, em concreto, entendido, sem grande contestação, até 1974.

O Direito, na sua marcha para plasmar novas realidades (ou, eventualmente, novas avocações da realidade...) pode ser uma resultante tanto de avanços científicos e doutrinais como de projectos ou propósitos políticos, porventura incutidos pelos media, por grupos, sindicatos, movimentos de cidadãos, correntes de opinião, que se constituem em fonte de inspiração, de influência e poder... No domínio da emigração, foi assim sendo imposta, em cada momento histórico, uma leitura da realidade não necessariamente coincidente com a verdade, tal como viam os seus protagonistas. A distância interposta entre os emigrantes e os centros de decisão política (e legislativa) era a distância geográfica, mas não só: era, também, uma marginalização de ordem social e política, que só foi - ou vai sendo... - superada pela sua capa- 
cidade de se fazer ouvir e compreender, levando à progressiva tomada de consciência geral das suas situações e dos problemas...

Políticas de sistemática protecção social e de apoio cultural aos emigrantes, em Portugal como em termos de Direito comparado, são relativamente recentes - coincidindo o seu início, em vários casos, com o termo de trágicos conflitos e provações colectivas - a última grande guerra mundial, a descolonização (em Portugal, tardia mas não menos determinante de uma maior solidariedade social, que directamente beneficiou os expatriados). Uma reviravolta que, no caso português, tivera a sua"pré-história" nas primeiras tímidas medidas de protecção social suscitadas pelo dramatismo de que se revestiu a chamada "emigração a salto" para a França e outros países vizinhos, a partir da década de 60.

\section{I.2. Do Paradigma "Territorialista" ao "Personalista"}

Voltemos ao Código Civil de 1867 para analisar as motivações do multissecular descaso dos poderes públicos pela sorte aos emigrantes.

Não haverá disposições mais reveladoras do modo de ver tradicionalmente o emigrante do que as que regem, uma vez perdida, durante o tempo de estada no estrangeiro, a nacionalidade portuguesa, a sua reaquisição, na hipótese de regresso. A perda automática era determinada pela atribuição de nacionalidade estrangeira - uma cominação que constituía, então, a regra, com uma argumentação que ainda hoje sustenta, em muitos países, a mesma solução: antes de mais, o dever de lealdade ao Estado, visto como "exclusivo" e "individual". Uma partilha de sentimentos e afectos em relação a dois países, ironizam alguns autores, assumia um carácter semelhante à do crime de bigamia: "In this concept, dual nationality is viewed as analogous to bigamy, amounting to a kind of cheeting in both polities" (ALEINIKOFF e KLUSMEYER, 2002:29).

Hoje, a tese contrária pretende basear-se na melhor compreensão da natureza humana, dos fenómenos de integração em sociedades abertas ao interculturalismo (por oposição àquelas que pretendem forçar, directa ou indirectamente, a "assimilação" dos estrangeiros), num quadro global de diluição de conflitos bélicos entre nações dadoras e receptoras de migrantes. Privilegiase a vontade de dupla pertença, da dupla cidadania, como a mais próxima do ser e querer das pessoas.

Portugal só viria a abolir o princípio da unicidade de nacionalidade em 1981 - não sem controvérsia, dentro e fora do parlamento. Em oitocentos, o Código de Seabra aderia à tese da unicidade - e nada de extraordinário se poderá apontar a tal opção... Extraordinário é, sim, o disposto no seu articu- 
lado, no respeitante à reaquisição da nacionalidade: após estipular que "perde a qualidade de cidadão português o que se naturalizar em país estrangeiro" dizia o art. $^{\circ} 22^{\circ}$ que "pode, porém, recuperar essa qualidade, regressando ao reino com ânimo de domiciliar-se nele, e declarando-o assim perante a municipalidade do lugar, que elegeu para domicílio". O artigo seguinte, sobre os efeitos da recuperação da nacionalidade, não dá a esta reaquisição, eficácia retroactiva: "[...] as pessoas só podem aproveitar desse direito desde o dia da sua reabilitação".

A denegação da retroactividade sublinha, de algum modo, o carácter de ruptura irreparável da ausência, pelo tempo em que perdura. Mas o legislador mostra perfilhar a concepção dos especialistas na matéria que só viam vantagem numa emigração se ida e volta, com a reinserção dos homens (ainda que num prazo dilatado pela necessidade de atingirem os seus objectivos económicos). Por isso, os emigrantes não se "desnacionalizam", em definitivo, e em caso de retorno uma simples manifestação da vontade os reinvestia no pleno exercício dos seus direitos de nacionais, sem o que o Estado tivesse meios de se lhes opor!

Note-se que, então, mais combatida ainda do que a emigração desmesurada, era a que se destinasse, com toda a probabilidade, a integração definitiva no estrangeiro. Boa emigração, útil para os protagonistas e para o Estado só a temporária... - temporária, ainda que de muito longa duração, num entendimento diverso do que hoje damos ao conceito.

Aqui residia, a meu ver, a verdadeira "ratio" da norma que facultava a reaquisição da nacionalidade por livre decisão individual. Estranhável é que se tenha perdido tão pertinente visão global do ciclo migratório, e, com ela, o intuito de facilitar a reintegração na comunidade de origem, ao adoptar, em posteriores leis da nacionalidade, solução menos "acolhedora", menos liberal, menos eficaz. Na verdade, todas as leis seguintes vieram impor, para além de uma complexa e quase sempre morosa tramitação burocrática, o "direito de oposição" do Estado à recuperação da nacionalidade. Poder discricionário que foi mantido na chamada "lei da dupla cidadania", embora não no texto da Lei $n^{0} 37 / 81$ de 3 de Outubro, que previa a reaquisição por "mera declaração do interessado", sem mais exigências, mas pela via regulamentar, que operou uma interpretação restritiva da norma, mantida por mais de duas décadas.

A admissão incondicional do pedido de recuperação da nacionalidade só veio a ser imposta (ou reposta, para os que defendem que a Lei de 81 foi descaracterizada em sede de regulamentação...) pela Lei Orgânica n ${ }^{\circ}$ 1/2004 de 15 de Janeiro. 
É de referir que houve, anteriormente, uma tentativa infrutífera de repristinar, parcialmente, a regra de recuperação automática da nacionalidade sancionada no Código Civil de 1867 -alargando-a às situações de permanência no estrangeiro, para tal dando à mera inscrição consular o mesmo efeito da declaração produzida, em caso de regresso, pelo emigrante oitocentista, perante as autoridades locais. (AGUIAR, 1999: 156). Refiro-me ao Projecto de Lei ${ }^{\circ} 140 /$ VIII que, apesar de não ter alcançado vencimento, constituiu um exemplo incomum de procura de uma solução para o futuro claramente inspirada na originalidade de velhos preceitos jurídicos.

Em 2004, encerra-se o último capítulo deste processo, que aglutinou não só políticos, mas "activistas" do que veio a considerar-se uma causa maior nas comunidades portuguesas de todo o mundo: não só é derrogado o "direito de oposição" estatal, como é garantida a retroacção dos efeitos da livre reaquisição da nacionalidade, por mera declaração de vontade. O cidadão é, doravante, o decisor único da sua pertença nacional, independentemente do lugar ou país de residência.

Um parêntesis, para olhar o que acontece na Europa, onde, neste campo, subsiste a divisão, no plano doutrinal e nos ordenamentos jurídicos internos - decorrente de experiências migratórias, antigas ou recentes, muito diversas- ou da sua falta. Uns são, ou foram, grandes países de origem de correntes migratórias. Outros são, essencialmente, destino desses movimentos... A nível do Conselho da Europa, a polémica prolongou-se por décadas, devido à inflexibilidade de blocos antagónicos, formados pelos Estados membros, que se afrontavam, mostrando pouco disponibilidade para negociar concessões... A Convenção de 5 de Maio de 1963 sobre a Redução dos Casos de Nacionalidade Múltipla, só veio a ser revogada, em 1997, pela Convenção Europeia sobre a Nacionalidade. Todavia, perante a irredutibilidade de alguns desses membros - nomeadamente a Alemanha, a generalidade dos países nórdicos, e não só... - o Conselho da Europa não foi além de uma posição de neutralidade na matéria.

Também não há consenso europeu na defesa do reconhecimento de um estatuto de direitos dos emigrantes, como mencionaremos adiante. No caso português, esse reconhecimento tem suporte constitucional, não só no que respeita à liberdade de circulação $\left(\right.$ art. $^{\circ} 44^{\circ}$ ), como em relação a novos direitos, que se englobam no "Direito dos Expatriados", uma construção jurídica em marcha, integrando "normas constitucionais, legais e regulamentares de direito interno e regras de direito internacional, tratados, convenções e princípios gerais de direito", como Barbosa de Melo teorizou no colóquio da Assembleia Parlamentar do Conselho da Europa (APCE) sobre "Os laços entre os europeus residentes no estrangeiro com os seus países de origem", reali- 
zado em 1997. No relatório da APCE baseado sobre os estudos preliminares, os debates e conclusões do colóquio, este Direito emergente foi considerado a resultante de um processo evolutivo centrado no cidadão e na possibilidade do seu relacionamento com o Estado em novos moldes: " the emerging law of expatriates has citizens interests at heart and not directly the interests of states" (AGUIAR and GUIRADO, 1999).

Os cidadãos vêem reconhecidos os direitos inerentes à qualidade de nacionais, independentemente da sua residência no estrangeiro - e, através deles, se impõe ao Estado a reestruturação das suas instituições e das suas leis, para que correspondam à dimensão humana do Nação e não apenas a uma organização de base territorial.

Segundo Bacelar de Gouveia, a nossa Constituição ensaia, desde 1976, gradualmente, a transição do paradigma "territorialista" para um paradigma "personalista" ou "nacionalista". Caminhamos, assim, nem sempre em linha recta, para a "desterritorialização" dos direitos dos emigrantes (um neologismo muito utilizado, em qualquer da línguas oficiais, nas actas do colóquio e do relatório da Assembleia Parlamentar do Conselho da Europa, acima referidos).

A Lei Fundamental portuguesa denuncia pulsões contraditórias entre a vontade de aumentar os direitos de participação de todos os cidadãos, e a de "dar menos direitos a quem está fora do território, porque não contribui para os impostos..." , como reconheceu o constitucionalista na audição parlamentar organizado pela Subcomissão das Comunidades Portuguesas, para examinar e reequacionar os chamados "Mecanismos Específicos de Representação de Emigrantes", (GOUVEIA, 2004:61).

Hoje, já não se discute a possibilidade teórica do exercício de direitos políticos a partir do estrangeiro, mas a sua denegação ou consagração, mais ou menos alargada traduz-se, "de jure constituto", em variadas formas de concretização. Entre elas se conta a adopção de meios específicos de representação de migrantes.

Um dos precursores do estabelecimento de tais meios, Emygdio da Silva, que chegou a propô-los, no começo do século XX, como sucedâneo para outras modalidades, então utópicas, de participação eleitoral de emigrantes, não precisaria de repetir agora o seu cauteloso comentário sobre a ousada proposta de um autor italiano, seu contemporâneo: "[...]sem pretendermos erigir em sistema as fantasias de um deputado italiano que, na Revista Económica Internacional aventava a ideia de que ao parlamento do seu país vies- 
sem representantes das colónias italianas em países estrangeiros [...]" (SILVA, 1917: 211).

Na verdade, as "fantasias" há muito se erigiram em sistema, no Direito em vigor em muitos Estados - incluindo em Portugal e Espanha, ainda que, em outros países, nomeadamente do norte da Europa, se mantenha o apego ao dogma da "territorialidade" -tal como no século XIX o teorizava Locke. Podemos, pois, também nesta questão, nesta "vexata questio", constatar a existência de uma Europa plural, dividida em muitas e diferentes sensibilidades no terreno das políticas migratórias...

\section{EMIGRAÇÃO - FORMAS MÚLTPLAS DE PRESENÇA}

"[...] Que ideia nos fazemos nós de Portugal: Somos o povo sediado no chão europeu, demarcado pelos nossos maiores, ou o povo que deve ser tomado e considerado independentemente do território que ocupa em cada tempo?"

António Barbosa de Melo

\section{II.1. No Interior do País}

A constatação das manifestações de presença, ou de pertença, dos expatriados foi irrompendo, cedo, despertada pelos "influxos financeiros" provocados pelos "fluxos migratórios" para o estrangeiro, relação de causa e efeito, crescentemente valorizada, nos meios políticos ou académicos, como na sociedade em geral - para o que contribuíam, sobremaneira, as características do nosso "emigrante tipo", o seu modo de se integrar num outro país, sem perda de ligação ao seu. Porquê? Antes de mais, porque a emigração portuguesa envolvia, numa primeira fase, quase exclusivamente homens, que partiam sós, mas com o objectivo de executar um plano familiar de melhoria de vida. A primeira modalidade de cumprimento desse projecto era o envio maciço de remessas: para as famílias a garantia de escapar à faixa larga de miséria ou de pobreza, para o Estado uma inesgotável fonte de divisas, indispensável ao equilíbrio das contas externas.

No primeiro quartel do século XX, Fernando Emygdio da Silva escrevia: "... É da emigração de miséria que a Pátria tira, depois, o ouro com que salda a conta da sua desorientação económica e dos desperdícios financeiros. É da miséria que vem a nossa maior riqueza: do pária nostálgico e atavicamente aventureiro... é que vem o ouro [...] não se esquecem de nos enriquecer com as remessas, que ainda ali não representam um excesso, mas, a maior parte das vezes, a privação, ao menos nos primeiros anos." (SILVA, 1917:107). 
Oliveira Martins, Afonso Costa, Anselmo de Andrade, Artur Bello, Vieira da Rocha, Egmydio da Silva são alguns dos autores que, nas suas estimativas, nos traçam os gráficos da enorme dependência nacional face ao prodigioso volume de remessas da emigração (SILVA, 1917: 105).

Estas prestações, tábua de salvação da economia portuguesa, configuram, assim, o modo mais antigo e mais reverenciado de os emigrantes aqui estarem presentes, não estando... E vão condicionar as políticas de emigração familiar, impondo fortes restrições à saída de mulheres e de menores, combatida em toda a medida do possível. O legislador tem em insignes juristas incondicional suporte. Afonso Costa qualifica o êxodo de mulheres como "[...] uma depreciação do fenómeno migratório [...]", porque: "[...] é quando a família do emigrante fica na Pátria, que ele envia mais regularmente as suas economias" (COSTA, 1913: 182). Na mesma linha de pensamento, Emygdío da Silva, para quem o crescente número de mulheres expatriadas, que, se verifica entre 1906 e 1913 (127\% de aumento) "é uma constatação tremenda". Com idêntica justificação:"[...] perigo de desnacionalização e cessação de remessas [...]" (SILVA, 1917: 132).

Vão os Homens, chegam as divisas, com as quais, de muito longe, imprimem marcas no território, influenciam a modernização de costumes, o consumo, o comércio, os transportes... Constroem ou reconstroem as casas, que, pelo seu porte, pelo gosto arquitectónico, inspirado em modelos estrangeiros se distinguem na paisagem rural ou na malha urbana, dando origem a críticas ambíguas ou díspares, a reacções de admiração, de mimetismo, de emulação, de inveja... Em qualquer caso, com elas conseguem testemunhar a "libertação" da pobreza antiga e escrever na pedra das moradias (no cimento, no azulejo, no ferro...) uma história de sucesso individual, que, em si, é, porventura, a manifestação de presença subjectivamente mais desejada. "Pour ces immigrés de première génération, il importe, surtout de rester portugais en France, mais encore plus de réussir le projet d'émigration qui leur permette de s'affirmer au Portugal comme ayant eu une réussite exemplaire [...]". " La réussite du projet n'est envisagée et n'a de sens que si elle est reconnue et donc traduite en réalisation - le plus souvent la construction d'une maison dans la communauté villageoise d'origine. [...]" (CUNHA, 1988:61).

As migrações podem mudar de rumo, de continente, de estatuto económico, que nem por isso há descontinuidade na predominância deste investimento em casas, quintas, terras que têm valor, quase sempre, sentimental, afectivo, para além do valor de mercado...

Dos palácios, palacetes, casarões de"brasileiros" do século XIX e inícios de novecentos (ROCHA TRINDADE, 2008: 143), passamos às vivendas mo- 
dernas de "franceses", "venezuelanos" e outros, de diversas proveniências geográficas, que, desde 60 e 70, proliferam em todas as regiões de forte emigração - edificações de raiz ou modificação de fachadas e arranjos estruturais ou de pormenor, com benfeitorias e traços ostensivamente "estrangeirados" . Como que a dizer que a aventura pelo mundo fora valeu a pena. Nada de muito diverso do que ocorre, por exemplo, em Cabo Verde ou na vizinha Galiza (MORA: 2008:284).

Outra forma de sublinhar o sucesso da aventura migratória e de o partilhar, quaisquer que sejam as motivações subjacentes - da legítima vontade de afirmação à solidariedade mais desinteressada e genuína - é a construção de obras de beneficência, a contribuição para instituições locais, o impulso dado ao melhoramento das condições de vida nas suas terras. Há uma tradição de generosidade, que teve um ponto alto, com as grandes fortunas do Brasil, e que se continua, à medida das posses de cada um, em cada novo ciclo migratório.

\section{II.2. Nas Comunidades do Exterior}

Se a presença dos emigrados através do bem-fazer nas terras de origem era bem conhecida dos conterrâneos, já não o era a vivência na sociedade de destino. A sua "descoberta" foi publicitada pelos primeiros estudiosos, que tiveram o privilégio de visitar as instituições fundadas pelos portugueses na "Diáspora". Afinal, proclamavam eles, os emigrantes levavam consigo Portugal - não o deixavam, simplesmente, para trás...

Mas não foram muitos - e não terão chegado a fazer escola... - os especialistas da emigração que, no princípio do século passado, reconheceram a existência dessa rede de organizações e deram testemunho do seu significado: Afonso Costa, Emygdio Silva são algumas das excepções à regra.

Afonso Costa iescrevia: "... além disso, formaram-se colónias portuguesas em São Francisco, Oackland, em New Bedford e Providence, Boston e Brooklin, tendo com principal fonte da emigração os Açores". E caracterizava a sua agregação nestes termos: "As colónias portuguesas resistem, têm individualidade, mantêm o nome, a língua, os usos portugueses", acrescentando que a formação das "colónias": "[...] torna a emigração útil para a Pátria, perdendo o carácter de abandono da Pátria".

É uma verdade, que intuiu antes de muitos na sua época: o "abandono da terra" cessa pela integração numa a "colónia" ou "comunidade" de vivência portuguesa. 
Por seu lado, Emygdio da Silva salientava "o sentimento associativo geral" entre os colonos portugueses do Brasil e chegava a uma conclusão, que pode, certamente, ser subscrita hoje em dia: "[...] a generosidade é a mais alta tradição da colónia portuguesa". (SILVA, 1917: 278). Deixou-nos, também, uma relação circunstanciada das associações mais importantes, algumas das quais permanecem com esse estatuto: a Caixa de Socorros Mútuos Dom Pedro V, o Gabinete de Leitura, o Clube Ginástico Português, no Rio de Janeiro, a Sociedade Portuguesa de Beneficência e o Centro Português em Santos, os Gabinetes de Leitura de Salvador e de Recife e outras notáveis instituições de Belém, Belo Horizonte, Manaus, São Luís de Maranhão, Curitiba...

Todavia, não creio que ambos estes grandes conhecedores das comunidades oriundas da emigração, na sua época - e muito menos quaisquer outros... - tenham tido plena consciência de que estavam perante formações capazes de sobrevivência para além do fim dos tempos da emigração (isto é, da primeira geração de emigrantes). E, ainda por cima, alicerçadas na emigração familiar que queriam evitar a todo o custo: a que não tinha regresso, e, por isso, se considerava votada à fatal "desnacionalização".

Estavam, evidentemente, certos quanto ao decréscimo de retornos no quadro da emigração familiar, mas não, como agora sabemos, no que respeita à capacidade de resistência à "dissolução cultural" das comunidades formadas por terceiras e quartas gerações de portugueses, que, por exemplo, na Califórnia - um destino de não regresso, por excelência - continuam a falar a língua e a manter vivos costumes e rituais religiosos trazidos por antepassados. Esta outra insuspeitada forma de presença - a das comunidades organizadas, a que as mulheres e os jovens deram densidade e futuro - só veio a ser plenamente reconhecida e a influenciar as políticas de emigração, nos anos seguintes ao 25 de Abril de 1974. Sobretudo a partir da criação, em 1980, do Conselho das Comunidades Portuguesas (CCP), um órgão representativo das organizações dos portugueses do estrangeiro, destinado a ser o interlocutor privilegiado do governo na definição e execução das políticas culturais e sociais, uma "[...] instituição medianeira entre a sociedade civil e o Estado" (AGUIAR, 1986:83).

\section{POLÍTICAS DE REENCONTRO}

«Portugal é mais uma cultura do que uma organização rígida» Francisco Sá Carneiro

\section{III.1. A Representação das Comunidades da Diáspora}

O reconhecimento da pertença dos emigrantes a uma Nação populacional 
ou "Nação de Comunidades", é coisa recente. Julgo que poderemos situar o ponto de viragem, nesta visão abrangente de nós mesmos, no I Congresso das Comunidades Portuguesas, realizado pela Sociedade de Geografia, em Setembro de 1964, a que se seguiu, dois anos depois, um segundo Congresso. Em muitas das intervenções aí registadas fica bem patente, o reconhecimento da inclusão dos expatriados no todo nacional. Numa frase lapidar, Gonçalves Cerejeira proclamava essa nova vontade de abrangência: "Onde está um português, aí está Portugal! “. Adriano Moreira, por seu lado, esclarecia que "a emigração não significa, de algum modo, o repúdio da condição originária de português. O portuguesismo é o património comum dos portugueses das sete partidas do mundo" (MOREIRA, 1981:345).

As comunicações encontram-se publicadas na revista da Academia Internacional da Língua Portuguesa, incluindo aquela em que Adriano Moreira fala de Portugal, "Nação peregrina" (MoREIRA, 1973: 57). Uma expressão muito glosada e que viria a inspirar novas designações parra a mesma ideia da diáspora portuguesa - tais como o "Portugal maior" de Vitorino Magalhães Godinho ou a "nação de comunidades" de Francisco Sá Carneiro - um novo "olhar", uma nova concepção de nós.

Na audição parlamentar de 2004 sobre a temática da representação dos "ausentes", a que aludimos, Adriano Moreira (o principal impulsionador destes Congressos, na qualidade de presidente da Sociedade de Geografia) foi convidado a traçar o quadro de preparação dessas iniciativas e seus objectivos. Segundo ele: "A ideia traduziu-se numa espécie de sistematização do que era a presença de Portugal no mundo, do ponto de vista das comunidades. Utilizamos uns conceitos operacionais que as arrumavam em três espécies". A primeira era composta pelos emigrantes de $1^{\text {a }}$ geração, a segunda pelos seus descendentes, que mantinham ligação às raízes, a terceira pelas comunidades filiadas na cultura portuguesa - obra também dos emigrantes, que "[...] aculturavam os povos por onde passavam". (AUDIÇÃo 2004:100).

Pelo empreendimento, inédito em Portugal, pela consciência da existência de um património histórico, que havia que preservar e potenciar, pela estratégia de criação de uma base institucional, para prosseguir esse projecto (com a criação da União das Comunidades - que teve efémera duração - e da Academia Internacional da Cultura Portuguesa), os dois Congressos da Sociedade de Geografia são precursores das políticas ditas "de reencontro", empreendidas a partir do final da década seguinte.

O primeiro "Congresso Mundial das Comunidades Portuguesas", depois de 1974, foi, como historiou o deputado Carlos Luiz, organizado, a partir de 1979, por uma Comissão que integrava elementos do Conselho da Revo- 
lução, sob a presidência de Vitor Alves, com o apoio do Presidente Ramalho Eanes (AUDIÇÃo 2004:36), mas viria a ser adiado para Junho de 1981 e levado a cabo por uma segunda comissão organizadora, presidida por Rosado Fernandes, um nome indicado pelo Governo. Se não foi efectivamente pioneiro, foi, de qualquer modo, o primeiro realizado sob a égide do Estado, com a presença de portugueses dos cinco continentes mundo, dirigentes das instituições em que se estrutura o espaço universal da cultura portuguesa, alguns dos quais haviam já respondido à chamada da Sociedade de Geografia, na década de 60 e integravam o Conselho das Comunidades Portuguesas $(\mathrm{CCP})$, cuja reunião fundadora se havia realizado dois meses antes, em Abril.

Criado em 1980, como dissemos, este órgão consultivo de representação das comunidades, era eleito no interior do movimento associativo, cuja capacidade de agregação e autenticidade se pretendia potenciar. Na óptica governamental, "[...] para garantia dessa autenticidade se baseou o processo de eleição dos representantes nas associações, que são a estrutura organizacional e os centros de vida das comunidades portuguesas do estrangeiro" (AGUIAR, 1986:84). Do preâmbulo da Lei $n^{\circ} 373 / 80$, resulta claramente a intenção de aproveitar a capacidade, o empenho, a autoridade moral de quem tem obra feita, respeitando a independência das instituições perante o Estado e face ao próprio "CCP", enquanto instituição pública: "O Conselho " [...] de modo algum pretende substituir-se aos movimentos preexistentes, pois se pressupõe ser condição de êxito deste projecto a vitalidade e capacidade de afirmação das próprias associações."

É na real autonomia da "sociedade civil" face ao Estado, trazendo ao "forum" de debate os seus próprios projectos, assim como no enfoque dado à força organizacional das comunidades, que este Conselho - ao contrário dos que mais tarde o haviam de continuar, em moldes distintos, à margem do centro de gravitação associativa - estava próximo do escopo e das preocupações metodológicas do movimento precursor de sessenta, como se evidencia nas palavras de Adriano Moreira, referindo-se aos congressos que dinamizou: "Qual foi o método que utilizamos? Foi partir em primeiro lugar da capacidade dessas associações e, por isso, o nosso ponto de referência foram as associações, sobretudo do Brasil, que era sempre o maior campo de observação" (AUDIÇão: 2004:63).

A "União" projectada na década de 60 , poderia, creio, ter dotado o movimento associativo das comunidades do estrangeiro de uma estrutura federativa, semelhante á que, de há muito, existe na maioria dos países europeus de emigração. Mas, como vimos, foi uma experiência logo interrompida. O CCP da década de 80 visava colmatar essa lacuna, e, do mesmo passo, dar 
início a um novo ciclo nas políticas para as comunidades portuguesas, como ressaltava do discurso oficial (AGUIAR, 2009:259). Mas também não atingiria esse objectivo primordial. $O$ órgão consultivo foi perdendo a sua centralidade e capacidade de interlocução, por falta de consulta e audição governamental e acabaria substituído por um novo "Conselho", que integrava um complexo conjunto de colégios eleitorais e que nunca funcionou plenamente.

Em 1996, o CCP foi reactivado, numa terceira configuração, passando a ser eleito por sufrágio directo e universal. O distanciamento do mundo associativo, acrescido da ambiguidade da sua própria natureza dual (órgão representativo, eleito directamente pelos emigrantes, órgão consultivo do governo...) não tem facilitado a interacção com o governo, a administração pública e os media nacionais, que o "Conselho" só conseguiu na sua primeira fase (AGUIAR, 2009:260).

É, em qualquer caso, o órgão de manifestação da "presença" dos expatriados, por excelência. Poderá, dar-lhes, a meu ver, com mais meios e mais audição, como reclamam os Conselheiros, a voz e visibilidade que os emigrantes ambicionam ter no país (e não têm tido).

Assim o julgou, também, a Subcomissão das Comunidades Portuguesas, que, por decisão unânime dos seus membros, promoveu duas sucessivas audições para reflexão sobre os modelos que melhor serviriam o futuro da instituição: o primeiro, em 2003, orientado para a procura de inspiração em soluções de direito comparado e na experiência de vida de órgãos semelhantes existentes na Suíça, em França, Itália, Espanha e Grécia; o segundo, a que fizemos várias menções, em 2004, para a avaliar a eventual "constitucionalização" do órgão, conferindo-lhe um carácter quase senatorial.

Constitucionalistas como Barbosa de Melo e Bacelar de Gouveia, assim como Adriano Moreira, intervieram no debate. Para Barbosa de Melo, a consagração da existência e das competências do CCP no texto da Constituição Portuguesa pode ser uma vantagem: Constitucionalizar, sim, "mas constitucionalizar como órgão do Estado português e não como órgão de Governo ou como órgão da Assembleia da República. Do que se trata aqui é de um instrumento para o exercício dos direitos fundamentais e constitucionais dos nossos compatriotas emigrados perante o Estado no seu conjunto". (AUDIÇÃO 2004:33).

Aberto à aceitação de uma emenda constitucional, mas recomendando prudência, Bacelar de Gouveia, acompanha essa posição: "É preciso não nos entusiasmarmos em demasia com a ideia da constitucionalização. Há muitas constitucionalizações e não só uma [...]" (AUDIÇÃO, 2004: 63). 
Outro tanto se poderia dizer do CCP, independentemente da sua entrada no "santuário" que a Lei fundamental configuraria, colocando-o fora do alcance do poder discricionário dos governos.

\section{III.2. Novos Direitos dos Expatriados}

A igualdade de direitos dos expatriados face aos residentes é hoje um reivindicação generalizada, ao menos nos países de "diáspora" - uma reivindicação para a qual o CCP foi, aliás, um instrumento de primeiro plano.

Na sua plenitude, a igualdade está longe de ser alcançada em Portugal. Faz parte do ideário de alguns partidos políticos, mas não, nos mesmos termos, nas de outros. Por isso, desde 1974, se tem caminhado, a par e passo, numa incessante busca de equilíbrios e de consensos, na Constituição e nas leis, para a afirmação gradual, progressiva de um estatuto de novos direitos culturais, sociais e políticos. O "estatuto dos expatriados".

\section{Direitos Culturais}

O Estado, assume, no Capítulo III, art. $^{\circ} 74$ da Constituição, a incumbência de " assegurar aos filhos dos emigrantes o ensino da língua portuguesa e o acesso à cultura portuguesa", mas incumpre largamente esse dever - e mais em determinados quadrantes geográficos do que noutros... Mais nas comunidades transoceânicas do que na Europa, a levantar a suspeita de que se vem privilegiando a emigração temporária, ou de retorno, como é (ou se pensava que fosse...) a do nosso continente. Por outras palavras: a língua é ensinada, sobretudo, na perspectiva do apoio à reinserção dos jovens de $2^{\mathrm{a}}$ geração e negligenciada como instrumento de preservação das comunidades de cultura portuguesa no mundo, nos destinos transoceânicos, da América do Norte à Oceânia, com algumas excepções (como Macau, Maputo e, em certa medida, a República da Âfrica do Sul).

Se a nível dos cidadãos não há igualdade de tratamento, nesta área estratégica, o mesmo acontece no plano institucional. $\mathrm{O}$ mundo associativo ao qual fizemos referências, tendo embora finalidades semelhantes ao que lhe serve de modelo em Portugal, deve-se inteiramente à iniciativa privada, apesar de prosseguir, em simultâneo, o escopo adicional de alargar o espaço da presença portuguesa, universalmente. Dentro de fronteiras poucas ONG's atingiriam os seus objectivos sem a robusta componente do apoio estatal, a ponto de se falar a seu respeito, frequentemente, de "subsídio - dependência". Fora do País, pelo contrário, a verdade é que nenhum centro social e cultural, grande ou pequeno, nenhum clube ou sociedade beneficente existiriam, se tivessem esperado por verbas do erário público para se constituir... Mesmo 
quando algum apoio acabaram por receber, no conjunto, ele foi, e é, diminuto.

\section{Direitos sociais}

Ao contrário do que acontece no domínio cultural, a Constituição não faz, no capítulo II, dedicado aos "Direitos e Deveres Sociais", qualquer expressa referência aos emigrantes.

É certo que o art. ${ }^{\circ} 63$, no seu $\mathrm{n}^{\circ} 1^{\circ}$, determina: "Todos têm direito à segurança social", tal como o art..$^{\circ} 74$, no seu $\mathrm{n}^{\circ} 1^{\circ}$, assegura: "Todos têm direito à educação e cultura". Todavia, neste outro capítulo, "todos" já são apenas todos os que residem no território... Uma das várias contradições flagrantes da nossa Lei Fundamental, no que às consequências da ausência do território respeita.

Tradicionalmente, como é sabido, o Estado quase se limitava a apoiar o repatriamento dos seus nacionais, em situações de extrema miséria. Um gesto de solidariedade que não configurava um direito, e ainda hoje se não encontra regulamentado como tal, apesar de ter sido, aprovado, na generalidade, um diploma que não chegou a ser apreciado na especialidade, nem objecto de votação final global. (AGUIAR, 2006:68).

Em anos recentes, pelo menos desde a década de 80, a Secretaria de Estado da Emigração concedia apoios pontuais em outras situações de necessidade, através dos seus serviços no estrangeiro, mas só em 1999 o Governo instituiu o Apoio Social a Idosos Carenciados (ASIC). Uma prestação de montante variável, de país para país, atribuída, com restrições, e longe de ser o equivalente de pensões não contributivas ou de mínimos de rendimento, tal como são garantidos dentro de fronteiras...

Em Direito comparado, há, actualmente, exemplos de sistemas de assistência na doença e na velhice, nomeadamente em países de emigração semelhante à nossa, como a Espanha ou a Itália - o que aumenta o sentimento de abandono de que os portugueses mais pobres se queixam, sobretudo em sociedades onde coexistem com emigrantes europeus melhor protegidos pelos Estados nacionais (caso do Brasil e da América de língua espanhola).

\section{Direitos Políticos}

O restabelecimento da democracia em 1974, veio dar aos emigrantes, pela primeira vez, direitos de participação na vida pública: inicialmente, apenas o de elegerem quatro deputados, em dois círculos eleitorais próprios - uma excepção ao princípio constitucional da proporcionalidade, pelo método de Hondt. 
Com a adesão à CEE, na qualidade de cidadãos europeus, ganharam o direito de voto nas eleições para o Parlamento Europeu, embora só desde 2004 esse direito tenha sido alargado aos que vivem fora do espaço da União Europeia (AGUIAR, 2006:85).

Foi preciso esperar pela revisão constitucional de 1997 para conseguirem o direito de voto na eleição do Presidente da República, após décadas de luta, que o $\mathrm{CCP}$ encabeçou. $\mathrm{O}$ sufrágio foi-lhes, porém, concedido com restrições. Têm capacidade eleitoral passiva apenas aqueles que comprovem, nos termos do $\mathrm{n}^{\circ} 2^{\circ}$ do art. $^{\circ} 121$, "laços de ligação efectiva à comunidade nacional".

Limitações cerceiam, igualmente, a participação dos emigrantes em "referenda" nacionais, admitida apenas quando "recaiam sobre matéria que lhes diga também especificamente respeito". O entendimento sobre a qualificação da matéria que especificamente "também" lhes respeita nunca foi pacífica mostra a lição da experiência ser questão em que os partidos, a começar pelos dois maiores, costumam divergir, obstaculizando a participação.

Para além da diversidade de universos eleitorais - para legislativas, para os "referenda" e para as presidenciais - há ainda a dualidade de modos de votação, visto que nas legislativas os emigrantes votam por correspondência, nas presidenciais e europeias, por sufrágio presencial. (MACHADO, 2009:41). Da participação nas eleições locais e autonómicas - que é facultada nos países europeus, dos quais nos sentimos próximos pela geografia e pela história das migrações - estão ainda excluídos, por força do texto constitucional.

Ao contrário do que acontece com as prestações sociais e com a extensão da rede de ensino, que acarretam custos substanciais, a concessão do voto não, pelo que as restrições estabelecidas resultam, obviamente, de falta de vontade ou consenso política, consequência de uma visão estreita da "comunidade política nacional" . Tem sido quase sempre difícil o consenso nesta matéria entre os dois partidos do "chamado "bloco central", PS e PSD, que, por si só, perfazem a maioria qualificada de dois terços, exigida para qualquer alteração constitucional ou para a aprovação de leis orgânicas, como são as eleitorais.

A divisão e o dissenso estendem-se, aliás, ao interior dos partidos. No que respeita ao alargamento do sufrágio, é o caso do PS. No PSD, aparentemente mais unido na reivindicação de igualdade de direitos políticos para todos os portugueses, podem apontar-se, por exemplo, mudanças radicais na forma de conceber a representação dos emigrantes no Conselho das Comunidades. 
Os expatriados têm fundadas razões de queixa de um sistema que prima pela falta de unidade e coerência e não lhes assegura o pleno exercício dos direitos de cidadania.

\section{CONCLUSÃO}

"Le Portugal est maintenant un petit pays de 90.000 kilométres carré, plus les iles atlantiques. Cependent, il est beaucoup plus que cela et il essaye de $s$ 'organiser comme nation en un petit territoire mais avec un peuple immense, dispersé sur tous les continents [...]" Francisco de Sá Carneiro

Primeiro- Ministro, discursando perante a APCE em 21 de Abril de 1980

A emigração portuguesa mudou desde os seus primórdios, mudou, mesmo que consideremos, apenas, a que aconteceu, em vários ciclos, no século passado, mas mudou certamente menos do que as leis, o discurso político ou a opinião pública sobre a sua natureza e sobre os efeitos jurídicos que esta deve determinar.

Olhares, discursos (no plural...) distintos sobre uma realidade migratória, que mantém muitos traços comuns: a realidade da saída de homens e mulheres - estas hoje, cada vez mais, em pé de igualdade - que abandonam o território por razões económicas e em massa (contra todas as expectativas geradas no período que se seguiu ao ingresso de Portugal na CEE); a existência de uma vasta rede de organizações de solidariedade e de fins culturais que decorrem da vivência colectiva no estrangeiro, em "comunidades"; a manutenção de relações de toda a ordem como país de origem, incluindo o envio de poupanças ainda vultosas.

No entanto, essas remessas, completamente ofuscadas pelos "fundos comunitários" deixaram de estar no centro das atenções, de ter o mesmo peso sociológico. Outros aspectos da emigração passaram, e não só por isso, a ser mais valorizados - caso da dimensão humana da"diáspora" e do reconhecimento património cultural, construído e preservado em muitos países do mundo, nas comunidades oriundas da emigração.

Em termos de estatuto jurídico, os emigrantes viram, desde 1974, respeitado e, desde 1976, consagrado constitucionalmente, o direito de livre circulação, e passaram a beneficiar de políticas de protecção extensivas a todo o ciclo migratório, da partida à estada no estrangeiro e ao regresso (ainda que não necessariamente executadas em termos ideais, e com os meios suficientes...). O princípio da igualdade entre todos os cidadãos, independentemente da residência é hoje aceite, embora dele se não tirem todas as possíveis consequências. 
Está, assim, consumada a adesão ao "paradigma personalista" - na tipologia de Bacelar de Gouveia. Nele cabem tanto políticas mais orientadas para a visão atomística do cidadão, com o seu estatuto de direitos face ao Estado, como as que privilegiam, também, a cooperação e a parceria institucional com as comunidades organizadas, dotadas de identidade e de coesão, criadoras de património cultural e formadas por um movimento associativo, capaz de reivindicação e de afirmação de formas próprias de presença portuguesa no mundo.

\section{BIBLIOGRAFÍA}

Aguiar, M. (1996): Política de Emigração e Comunidades Portuguesas, Secretaria de Estado da Emigração e Comunidades Portuguesas, Porto, Centro de Estudos.

Aguiar, M. (1987): Política de Emigração e Comunidades Portuguesas, $2^{\mathrm{a}}$ edição, Porto, Centro de Estudos.

Aguiar, M. (2004): Círculo de Emigração, Lisboa, Edição de Autor.

Aguiar, M. M. (2006) - Comunidades Portuguesas - Os Direitos e os Afectos, Porto, Edição de autor.

AguiAR, M. (2009): «O CCP e a representação dos Emigrantes» in Migrações, Revista do Observatório da Imigração, $\mathrm{n}^{\circ} 5$, Migrações entre Portugal e a América Latina.

AguiAR, M. and Guirado, A. (Rapporteurs) (1999): «Links Between Europeans Living Abroad and their Countries of Origin», Parliamentary Assembly of the Council of Europe, Committee on Migrations, Refugees and Demography.

Aleinikoff, T. A. and KlusmeYer, D. (2002): Citizenship Policies for an Age of Migration. Washington D. C., Carnaggie Endowment for International Peace.

Alves, J. F. (2003): «Perspectiva Histórica da Emigração Portuguesa» in Porto de Partida, Porto de Chegada - A emigração Portuguesa, Lisboa, Âncora Editora.

CostA, A. (1911): Problema da Emigração, Lisboa, Imprensa Nacional.

CunHA, M. do C. (1998): Portugais de France, 1998, París, Harmattan.

GouveIA, B. de (2004): in Mecanismos Específicos de Representação de emigrantes.

MACHADO, J. (2009): «Cidadãs da Diáspora - Encontro em Espinho», Edição "Mulher Migrante - Associação de Estudo, Cooperação e Solidariedade".

Melo, A. B. (2004): in Mecanismos Específicos de Representação de Emigrantes.

MARTINS, O. (1994): Fomento rural e emigração, Lisboa, Guimarães Editora, $3^{\text {a }}$ edição.

MORA, P. L. (2009): «Galiza: Migraciones e Transformación de vivenda vernacular. Novidades e persistencias» in Rocha Trindade, M. B. (org.), Migrações, Permanências e Diversidade, Lisboa, Edições Afrontamento.

MoreIRA, A. (1981): Academia Internacional da Cultura Portuguesa, Boletim no 11 $-1979 / 80 / 81$.

MoreIRA, A. (2004): in Mecanismos Específicos de Representação de Emigrantes.

SERRÃo, J. (1974): A emigração Portuguesa. Lisboa, Livros Horizonte.

SiLVA, F. E. da (1917)- Emigração Portuguesa, Coimbra, França e Arménio. 
Subcomissão das Comunidades Portuguesas (2004): Mecanismos Específicos de representação de Migrantes - Audição Parlamentar, Lisboa, Assembleia da República.

TRINDADE, M. B. R. (2003): «Refocalizar a Imagem do Brasileiro» in Olhares Lusos e Brasileiros, São Paulo, Usina do Livro. 